\section{Acute extrapyramidal symptoms following abrupt discontinuation of propranolol}

Sir - A case of acute extrapyramidal manifestations consisting of dystonia and akathisia following abrupt discontinuation of propranolol is reported. She responded well to oral propranolol and intramuscular diazepam. Extrapyramidal symptoms have commonly been associated with acute or chronic administration of neuroleptic drugs. There have been reports of a substantial number of cases with similar clinical characteristics associated with the tricyclic antidepressants, monoamine oxidase inhibitors, and selective serotonin reuptake inhibitors. Although it is known that beta-adrenoceptor antagonists are effective in the treatment of extrapyramidal symptoms especially akathisia, there has been no previous report of such symptoms induced by abrupt withdrawal of these drugs. Although she had been on low dose of amitriptyline and had discontinued this medication long before, prolonged use of amitriptyline may have had a predisposing role in the development of these symptoms.

Extrapyramidal symptoms include acute dystonias, akathisia, Parkinson's syndrome and tardive dyskinesia. These symptoms are common manifestations of neuroleptic drugs. Other drugs inducing similar clinical characteristics include the tricyclic antidepressants, monoamine oxidase inhibitors, and selective serotonin reuptake inhibitors.'

Although it is known that beta-adrenoceptor antagonists are effective in the treatment of extrapyramidal symptoms especially akathisia, ${ }^{2}$ there has been no report of such symptoms induced by abrupt withdrawal of these drugs.

\section{Case report}

A 30 year-old lady presented with agitation, restlessness, nausea, and spasmodic contraction of jaw muscles causing involuntary deviation of the lower jaw to the left. She described feeling of "being pulled down by the gravity". She had never experienced such symptoms before. Thorough physical examination with special focus on the nervous system was unremarkable except for the involuntary contraction of jaw muscles and a fine tremor in her extremities.

The patient had been on long-term propranolol $10 \mathrm{mg}$ twice daily for a mitral valve prolapse. She had stopped using her drug two days before this problem due to misbelief that she may become addicted to the drug. She also had a history of using amitriptyline $25 \mathrm{mg}$ before sleep for insomnia, but had stopped using this drug long before. She had no other significant drug history.

The patient was managed with $10 \mathrm{mg}$ intramuscular diazepam and $10 \mathrm{mg}$ oral propranolol and was symptom free in two hours. She was instructed to continue her propranolol as usual.

Propranolol has been used for the treatment of neuroleptic induced extrapyramidal manifestations especially akathisia. . $^{3.3}$ Other extrapyramidal manifestations such as tardive dyskinesia and pseudoparkinsonism have also been well managed with propranolol. ${ }^{4-7}$ It has also shown effectiveness in ameliorating levodopa-induced ballistic and choreic dyskinesia in Parkinson's disease. ${ }^{8}$ Reports on use of other beta-adrenoceptor antagonists are more controversial but trends are toward their efficacy and safety. ${ }^{9,10}$

Extrapyramidal symptoms have commonly been associated with acute or chronic administration of neuroleptic drugs. There have been reports of a substantial number of cases with similar clinical characteristics associated with the tricyclic antidepressants, monoamine oxidase inhibitors, and selective serotonin reuptake inhibitors. ${ }^{1}$ There has been no report of extrapyramidal symptoms following withdrawal of propranolol. This reported patient is a case of acute extrapyramidal manifestations consisting of dystonia (spasmodic contraction of jaw muscles causing involuntary deviation of the lower jaw to the left) and akathisia (agitation, restlessness, and feeling of "being pulled down by the gravity") following abrupt discontinuation of propranolol. She responded well to oral propranolol and intramuscular diazepam. The coincidence of propranolol withdrawal and these symptoms, the finding of no other causes or events to explain, and the patient's excellent response to propranolol are convincing evidence that these extrapyramidal symptoms were, at least in part, related to propranolol withdrawal. More reports may establish this relation.

Tricyclic antidepressants such as amitriptyline are also associated with extrapyramidal symptoms. ${ }^{1.11}$ These symptoms are often dose-related, and respond to antiparkinsonian agents or propranolol. In some cases, they can disappear even though the same dose of tricyclic antidepressant is continued. Although she had been on a low dose of amitriptyline and had discontinued this medication long before, prolonged use of amitriptyline may have had a predisposing role in the development of these symptoms.

\section{Ahmad Alavian Ghavanini, Nemazee Hospital, Post Code: 71935, Shiraz, Iran \\ E-mail: alavianm@sums.ac.ir}

\section{References}

1. Gill HS, DeVane CL, Risch SC. Extrapyramidal symptoms associated with cyclic antidepressant treatment: a review of the literature and consolidating hypotheses. J Clin Psychopharmacol 1997; 17(5): 377-89.

2. Holloman LC, Marder SR. Management of acute extrapyramidal effects induced by antipsychotic drugs. Am J Health Syst Pharm 1997; 54(21): 2461 . 77.

3. Kulik AV, Wilbur R. Case report of propranolol (Inderal) pharmacotherapy for neuroleptic-induced akathisia and tremor. Frog Neuropsychopharmacol Biol Psychiatry 1983; 7(2-3): 223-5.

4. Chaudhry R, Radonjic D, Waters B. Efficacy of propranolol in a patient with tardive dyskinesia and extrapyramidal syndrome. Am J Psychiatry 1982 May; 139(5): 674-6.

5. Wilbur R, Kulik FA. Propranolol (Inderal) for tardive dyskinesia and extrapyramidal side effects from neuroleptics: possible involvement of betaadrenergic mechanisms. Frog Neuropsychopharmacol 1980; 4(6): 627-32.

6. Kulik FA, Wilbur R. Propranolol for tardive dyskinesia and extrapyramidal side effects (pseudoparkinsonism) from neuroleptics. Psychopharm Bull 1980; $16(3): 18-9$

7. Gelenberg AJ. Treating extrapyramidal reactions: some current issues. J Clin Psychiat 1987 Sep; 48 (Suppl): $24-7$.

8. Carpentier AF, Bonnet AM, Vidailhet M, Agid. Improvement of levodopainduced dyskinesia by propranolol in Parkinson's disease. Neurology 1996; Jun; 46(6): $1548-51$.

9. Kikuchi T, Uwahodo Y, Tottori K, Nakai M, Morita S. The attenuating effect of carteolol hydrochloride, a beta-adrenoceptor antagonist, on neurolepticinduced catalepsy in rats. Psychopharmacology Berl 1997; 131(2): 108-14.

10. Wells $\mathrm{BC}$ et al. A placebo-controlled trial of nadolol in the treatment of neuroleptic-induced akathisia. J Clin Psychiar 1991; 52(6): 255-60.

11. Vandel $P$ et al. Tricyclic antidepressant-induced extrapyramidal side effects. Eur Neuropsychopharmacol 1997; 7(3): 207-12. 


\section{Depression}

\section{Breakthrough}
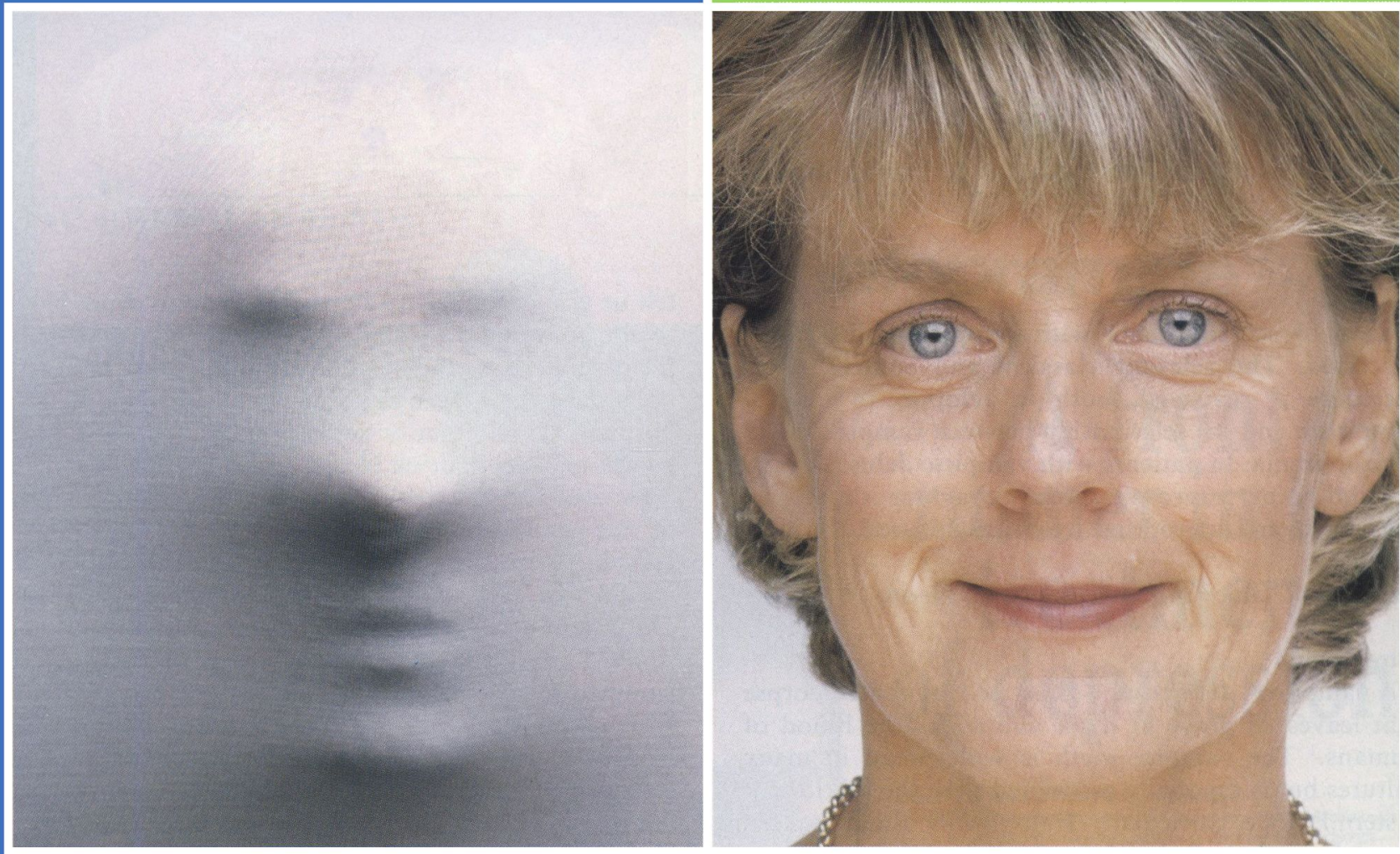

\section{A totally new treatment for people facing depression}

Edronax is a selective Noradrenaline Reuptake Inhibitor (selective NRI), a new generation of antidepressant, with proven efficacy in all grades of depression with or without associated anxiety.'

Well tolerated, this new treatment is also 'particularly useful in the elevation of patients' motivation, energy and drive'.?

\section{NEW}

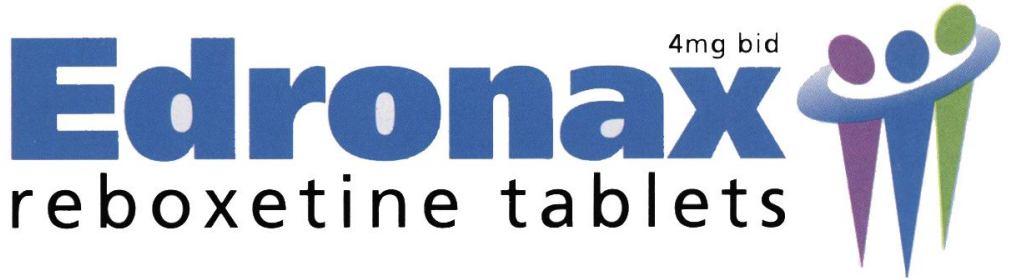

\section{Released from depression Reunited with the world}

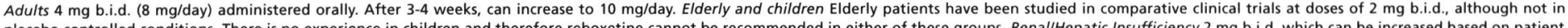

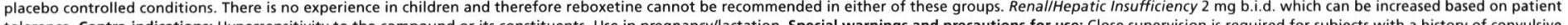

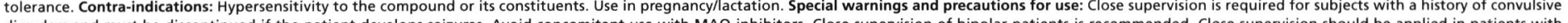

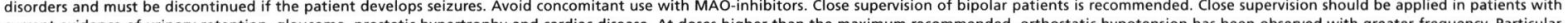

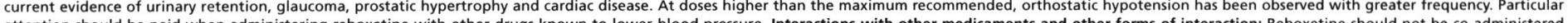

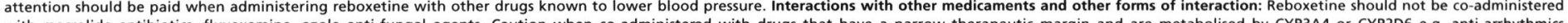

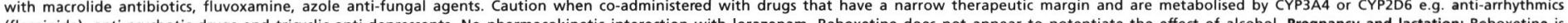

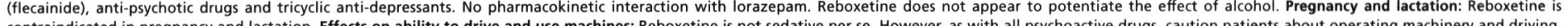

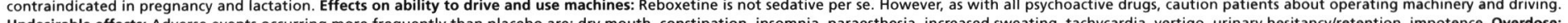

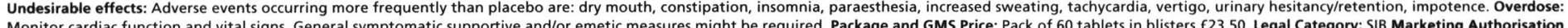

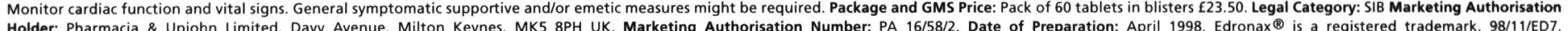

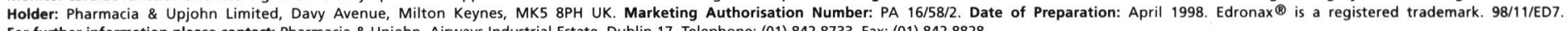

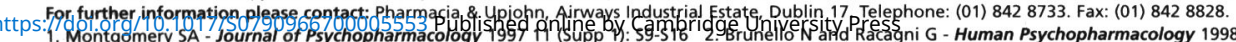

